\title{
ARMAZENAMENTO DE CAJÁS RECOBERTOS COM FÉCULA DE MANDIOCA E FILME DE CLORETO DE POLIVINILA
}

\author{
Raimunda Valdenice da Silva Freitas ${ }^{1}$, Pahlevi Augusto de Souza ${ }^{2}$, Evando Luiz Coelho ${ }^{3}$, \\ Hirllen Nara Bessa Rodrigues Beserra ${ }^{4}$, José Darcio Abrantes Sarmento ${ }^{5}$, Diogenes
} Henrique Abrantes Sarmento ${ }^{6}$

\footnotetext{
${ }^{1}$ Mestre em Tecnologia de Alimentos, Professora da Faculdade de Tecnologia Centec - Sertão Central, Quixeramobim, Ceará (CE).

${ }^{2}$ Doutor em Fitotecnia, Professor do Instituto Federal de Educação, Ciência e Tecnologia do Ceará (IFCE), Campus Limoeiro do Norte - CE.

${ }^{3}$ Doutor em Fitotecnia, Professor do Instituto Federal de Educação, Ciência e Tecnologia do Sul de Minas, Inconfidentes, Minas Gerais.

${ }^{4}$ Mestre em Tecnologia de Alimentos, Professora do Instituto Federal de Educação, Ciência e Tecnologia do Rio Grande do Norte, Campus Pau dos Ferros, Rio Grande do Norte (RN).

${ }^{5}$ Doutorando em Fitotecnia pela Universidade Federal Rural do Semi-Árido (UFERSA), Mossoró - RN.

${ }^{6}$ Doutorando em Manejo de Solo e Água pela UFERSA, Mossoró - RN.
}

RESUMO: Objetivou-se neste trabalho avaliar a conservação pós-colheita de frutos de cajá recobertos com fécula de mandioca e filme de cloreto de polivinila (PVC). Para realização desse trabalho utilizou-se frutos de cajá do genótipo 'Lagoa Redonda' colhidos em Limoeiro do Norte - CE, em maturidade fisiológica (de vez). Posteriormente os frutos foram transportados ao Laboratório de Química de Alimentos do IFCE Campus Limoeiro do Norte e armazenados por 8 dias a $29,7{ }^{\circ} \mathrm{C}$ e $59 \%$ de umidade relativa (UR). O delineamento experimental foi o inteiramente casualizado em esquema fatorial 3 x 5 , com três tipos de revestimento (controle, fécula de mandioca a $3 \%$ e fécula de mandioca a $3 \%$ associado ao filme de PVC) e cinco tempos de armazenamento (0, 2, 4, 6 e 8 dias), com quatro repetições de cinco frutos por parcela. Durante o experimento foram avaliadas as seguintes características: coloração da casca, aparência externa, teores de sólidos solúveis (SS) e de acidez titulável (AT), relação SS/AT e a perda de massa. Concluiu-se que o uso do filme plástico foi eficiente para conservação da aparência externa, redução da perda de massa e atrasar o amarelecimento dos frutos. $\mathrm{O}$ uso da fécula de mandioca não se mostrou tão eficiente em reduzir a perda de massa quanto ao filme de cloreto de polivinila na conservação de cajás. A vida útil pós-colheita dos frutos foi de até 8 dias para os tratados com fécula de mandioca ou fécula de mandioca associada ao PVC e 6 dias para o controle.

Palavras-chave: Spondias mombin L. Revestimento. Conservação. Pós-colheita. Vida útil.

\section{STORAGE OF YELLOW MOMBIN FRUITS COVERED WITH CASSAVA STARCH AND POLYVINYL CHLORIDE FILM}

\begin{abstract}
This study aimed to evaluate the postharvest conservation of yellow mombin fruits coated with cassava starch and polyvinyl chloride film. Were used fruits of yellow mombin Lagoa Redonda genotype harvested in Limoeiro do Norte-CE in mature green
\end{abstract}


stage. Then the fruits were transported to Food Science Laboratory of IFCE Campus Limoeiro do Norte - CE and stored for 8 days at room temperature of $29.7{ }^{\circ} \mathrm{C}$ and relative humidity (RH) 59\%. A 3 x 5 factorial scheme with four replications of five fruits per plot in a completely randomized design was used. The treatments consisted of the combination of three coating types (control, cassava starch and cassava starch associated with polyvinyl chloride film - PVC) with five storage times (0, 2, 4, 6 or 8 days). Peel color, external appearance, soluble solids, titratable acidity, Ratio (SS/TA) and weight loss were evaluated during storage. It was concluded that the use of plastic film was effective for preserving the external appearance, reduction of weight loss and delay yellowing of the fruit. The use of cassava starch was not as efficient in reducing the weight loss as the polyvinyl chloride film for conserving mombin fruits. The shelf-life was up to 8 days for treated with cassava starch or cassava starch associated with PVC and six days for the control.

Key words: Spondias mombin L. Coating. Conservation. Postharvest. Shelf life.

\section{INTRODUÇÃO}

A cajazeira (Spondias mombin L.) pertence à família Anacardiaceae e ao gênero Spondias. É uma árvore frutífera tropical lenhosa, de tronco longo, ereto e porte alto (DUVALL, 2006). Seu fruto, o cajá, tem despertado o interesse dos produtores, pesquisadores, indústria e do mercado nacional e internacional em razão das diversas possibilidades de uso, ótimas características nutricionais e alto potencial para processamento (TIBURSKI et al., 2011). Porém, a alta perecibilidade é um dos pontos críticos que prejudicam a agregação de valor ao longo da cadeia de comercialização (MOREIRA et al., 2002).

Existem vários métodos de conservação, os quais destacam-se, além da refrigeração, a atmosfera modificada, amplamente utilizada na preservação da qualidade dos produtos vegetais, contribuindo para o decréscimo de perdas pós-colheita (VILA et al., 2007). Nos últimos anos, houve um interesse crescente pelo desenvolvimento de formulações de filmes e coberturas comestíveis aplicáveis à superfície de produtos perecíveis, em blueberry (DUAN et al., 2011), berinjela (SOUZA et al., 2009), ameixa (EUM et al., 2009), goiaba (VILA et al., 2007) e morango (RIBEIRO et al., 2007). Sendo a fécula de mandioca considerada a matéria-prima mais adequada na elaboração de biofilmes comestíveis (HOJO et al., 2007).

Esse fato advém da demanda crescente dos consumidores por produtos de elevada qualidade e vida útil prolongada. Além disso, também tem sido considerada a redução no uso de embalagens descartáveis que não são biodegradáveis (CHITARRA; CHITARRA, 2005), podendo assim, possibilitar a redução de resíduos que podem causar sérios problemas ambientais.

Contudo isso, face à necessidade de aumentar a vida útil, reduzir os danos e perdas pós-colheita de espécies frutíferas como o cajá, passa a ser importante o conhecimento e a aplicação de técnicas adequadas capazes de assegurar a manutenção da qualidade dos frutos,

Cultura Agronômica, Ilha Solteira, v.25, n.4, p.409-418, 2016 
proporcionando um melhor aproveitamento do seu potencial de comercialização. Deste modo, o objetivo deste trabalho foi avaliar a conservação pós-colheita de frutos de cajá recobertos com fécula de mandioca e filme de PVC.

\section{MATERIAL E MÉTODOS}

Os frutos de cajá utilizados neste experimento, foram do genótipo 'Lagoa Redonda' colhidos em pomar localizado em área do Instituto Frutal a $5^{\circ} 12^{\prime}$ 9,8” S e $37^{\circ} 59^{\prime}$, 29,2” W e altitude de 158 m (GPS 12), no DIJA - Distrito de Irrigação Jaguaribe-Apodi, em Limoeiro do Norte-CE, apresentando estádio de maturação fisiológica verde (de vez). Em seguida, foram transportados para o laboratório de Química de Alimentos do Instituto Federal de Educação, Ciência e Tecnologia do Ceará - IFCE, Campus Limoeiro do Norte, onde foram selecionados e sanitizados com solução de cloro ativo $(0,01 \%)$. Parte dos frutos foi recoberta com suspensão de fécula de mandioca a 3\%, outra parte foi recoberta com esta suspensão de fécula de mandioca associado ao filme de cloreto de polivinila (PVC) da Alp Film ${ }^{\circledR}$, esticável e autoaderente, com $15 \mu \mathrm{m}$ de espessura, e os demais frutos foram mantidos sem tratamento. Os frutos foram armazenados em ambiente com temperatura média de $29,7^{\circ} \mathrm{C}$ e $59 \%$ de UR medidas com auxílio de termo-higrômetro Minipa MT-241.

A emulsão de amido foi preparada misturando-se em 1 litro de água e $30 \mathrm{~g}$ de fécula, com aquecimento a $70{ }^{\circ} \mathrm{C}$, sob agitação constante até que sua geleificação fosse atingida. Esta preparação foi mantida em repouso até alcançar temperatura ambiente para posterior imersão dos frutos de cajá.

O delineamento experimental utilizado foi o inteiramente casualizado em esquema fatorial 3 x 5, que consistiram nos tipos de revestimento (controle, fécula de mandioca a $3 \%$ e fécula de mandioca a $3 \%$ associado ao filme de cloreto de polivinila - PVC) e tempos de armazenamento $(0,2,4,6$ e 8 dias), com 4 repetições, sendo cada repetição composta por 5 frutos.

A cada tempo de armazenamento foram avaliadas as seguintes características: aparência externa, realizada através de uma escala visual e subjetiva variando de 1 a 5 , onde 5: representa o fruto com ausência de depressões, manchas ou ataque de microrganismos, 4: fruto com traços de depressões e/ou manchas, 3: fruto com depressões e/ou manchas leves, 2: fruto com depressões e/ou manchas com média intensidade, 1: fruto com depressões e/ou manchas com intensidade severa ou ataque de microrganismos e 0: fruto com depressões e/ou manchas com intensidade muito severa ou ataque generalizado de microrganismos (LIMA et al., 2004), considerando-se a ausência ou presença de defeitos, murcha e ataque fúngico; coloração da casca, realizada através de uma escala visual e subjetiva variando de 1 a 5, onde 1: representa o fruto totalmente verde, 2: fruto com $25 \%$ da casca amarela, 3 : fruto com $50 \%$ da casca amarela, 4: fruto com $75 \%$ da casca amarela e 5: fruto totalmente amarelo; teor de sólidos solúveis (SS), determinado após os frutos serem descascados, despolpados e a polpa processada em centrífuga doméstica, sendo determinado no suco filtrado usando-se refratômetro digital e os resultados expressos em ${ }^{\circ}$ Brix; teor de acidez titulável (AT), através de titulação de uma alíquota de $5 \mathrm{~mL}$ da amostra com solução de

Cultura Agronômica, Ilha Solteira, v.25, n.4, p.409-418, 2016 
$\mathrm{NaOH}$ 0,1 mol L $\mathrm{L}^{-1}$, os resultados expressos em \% de ácido cítrico, seguindo as Normas Analíticas do Instituto Adolf Lutz (ZENEBON et al., 2008) e relação SS/AT (Ratio), calculada pelo quociente entre os teores de sólidos solúveis e de acidez titulavel. A perda de massa foi avaliada diariamente, através da diferença entre a massa inicial e massa obtida a cada intervalo de tempo, com os resultados expressos em porcentagem.

Os dados obtidos foram submetidos à análise de variância. Para o fator qualitativo utilizou-se o teste de Tukey a 5\% de probabilidade e para o fator quantitativo, análise de regressão, através do programa Table Curve (JANDEL SCIENTIFIC, 1991).

\section{RESULTADOS E DISCUSSÃO}

Observou-se interação significativa entre os fatores estudados para as características acidez titulável, cor e aparência externa. Houve efeito isolado do fator tipos de revestimento para as características sólidos solúveis e perda de massa e do fator tempo de armazenamento para as características sólidos solúveis, perda de massa, ratio e $\mathrm{pH}$.

Houve aumento gradual de perda de massa ao longo do período de armazenamento (Figura 1A) com valor máximo de $15,66 \%$ aos 8 dias. Para os tratamentos, verificou-se maior perda de massa para os frutos recobertos com fécula isoladamente com valor médio de $10,76 \%$, cerca de $26,02 \%$ superior aos demais tratamentos, porém não sendo suficiente para causar alteração na aparência dos frutos (Figura 1B).
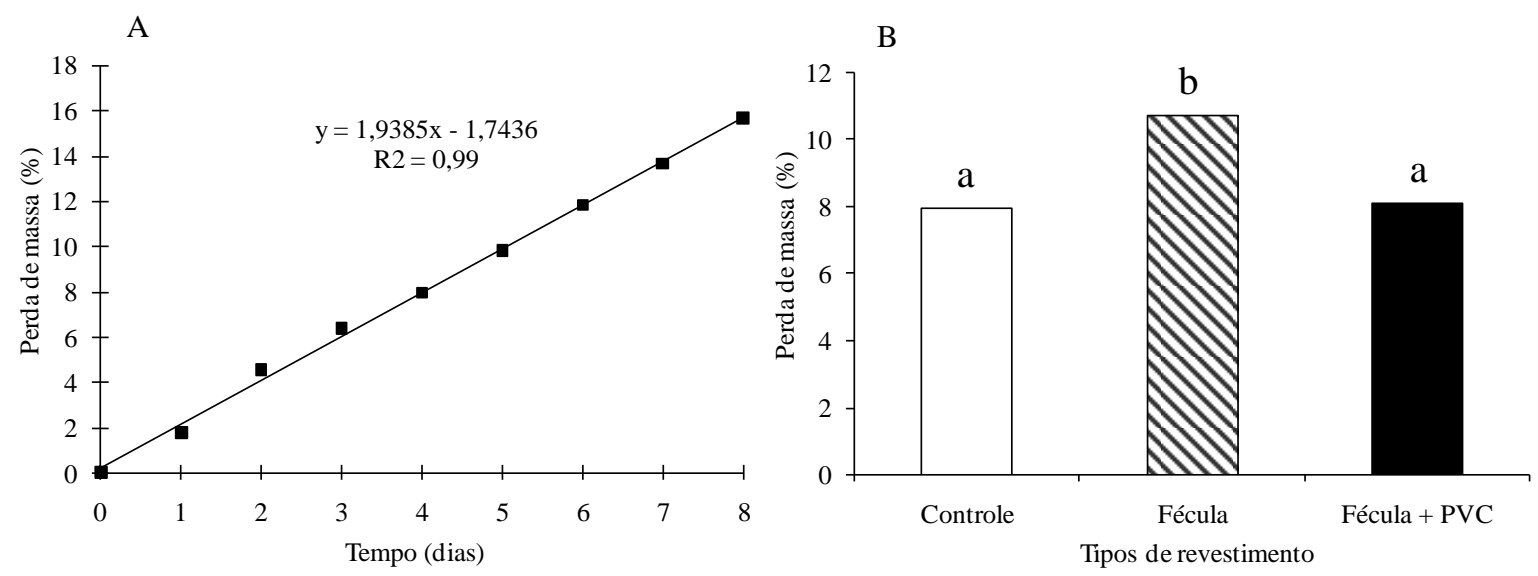

Figura 1. Valores de Perda de massa (A) e (B) de frutos de cajá recobertos com diferentes tipos de revestimentos e armazenados por 8 dias sob temperatura média de $29,7{ }^{\circ} \mathrm{C}$ e UR de $59 \%$.

Essa perda de massa ocorre principalmente devido a perda de umidade do produto ocasionada pelo processo transpiratório. Sabe-se que a fécula de mandioca não apresenta bons resultados quanto à retenção de umidade devido à estrutura da cadeia de amido e em alguns casos o amido poderá funcionar como uma substância hidrofílica, retirando umidade do fruto. Sarmento et al. (2015), observaram comportamento semelhante em banana 'Prata Catarina' recoberta com biofilmes de fécula a $3 \%$ e armazenada a $27,5{ }^{\circ} \mathrm{C}$ e UR de $62,5 \%$, observando perdas de $15,82 \%$ após 10 dias de armazenamento. Resultados semelhantes 
também foram observados por Lemos et al. (2007), que avaliando o efeito de biofilmes de fécula de mandioca nas concentrações de 3,4 e 5\% sobre a conservação de pimentões 'Magali R' armazenados em duas condições de armazenamento, verificaram que, sob temperatura ambiente, o biofilme não reduziu a perda de massa e, sob condições de refrigeração, os frutos tratados com o biofilme perderam mais massa que o controle. Pereira et al. (2006), utilizando revestimento com fécula de mandioca nas concentrações de 1,2 e $3 \%$, em mamão, também não observaram redução significativa na perda de massa. Também verificaram menor perda com o aumento da concentração da fécula na suspensão (PEREIRA et al., 2006; LEMOS et al., 2007).

Segundo Chitarra e Chitarra (2005), o uso de coberturas hidrofílicas, como o amido, tem limitações quanto às propriedades de barreira de vapor d’água. Para sanar tal limitação poderia se adicionar ao filme comestível algum lipídeo ou proteína. Quanto à utilização do filme plástico, Al-ati e Hotchkiss (2003) observaram que o aumento na vida útil póscolheita de frutas pode ser obtido pelo uso de filmes flexíveis, que agem como agentes modificadores da atmosfera, minimizando a perda de água (CISNERO-ZEVALLOS; KROCHTA, 2002). Moretti e Pineli (2005), usando diferentes atmosferas em berinjelas armazenadas sob refrigeração a $12{ }^{\circ} \mathrm{C}$, observaram reduzida perda de massa com o uso do filme plástico, associado ou não ao $\mathrm{CaCl}_{2}$, em relação ao controle. Assim, o PVC mostra-se efetivo na contenção de perda de massa, provavelmente, devido à redução da taxa respiratória nos frutos e também por formar importante barreira contra a perda de água (VILA et al., 2007).

Nos teores de sólidos solúveis (SS), observou-se aumento ao longo do período de armazenamento de 9,2 ${ }^{\circ}$ Brix para $11,3^{\circ}$ Brix (Figura 2A), apresentando teores máximos no $4^{\circ}$ dia de armazenamento. Já para os tipos de revestimento, verificou-se que o tratamento fécula associado ao PVC apresentou os menores teores de SS (11,0 ${ }^{\circ}$ Brix $)$, já os tratamentos controle $\left(11,5^{\circ}\right.$ Brix $)$ e fécula $\left(11,6^{\circ}\right.$ Brix $)$ os maiores teores (Figura $\left.2 \mathrm{~B}\right)$.
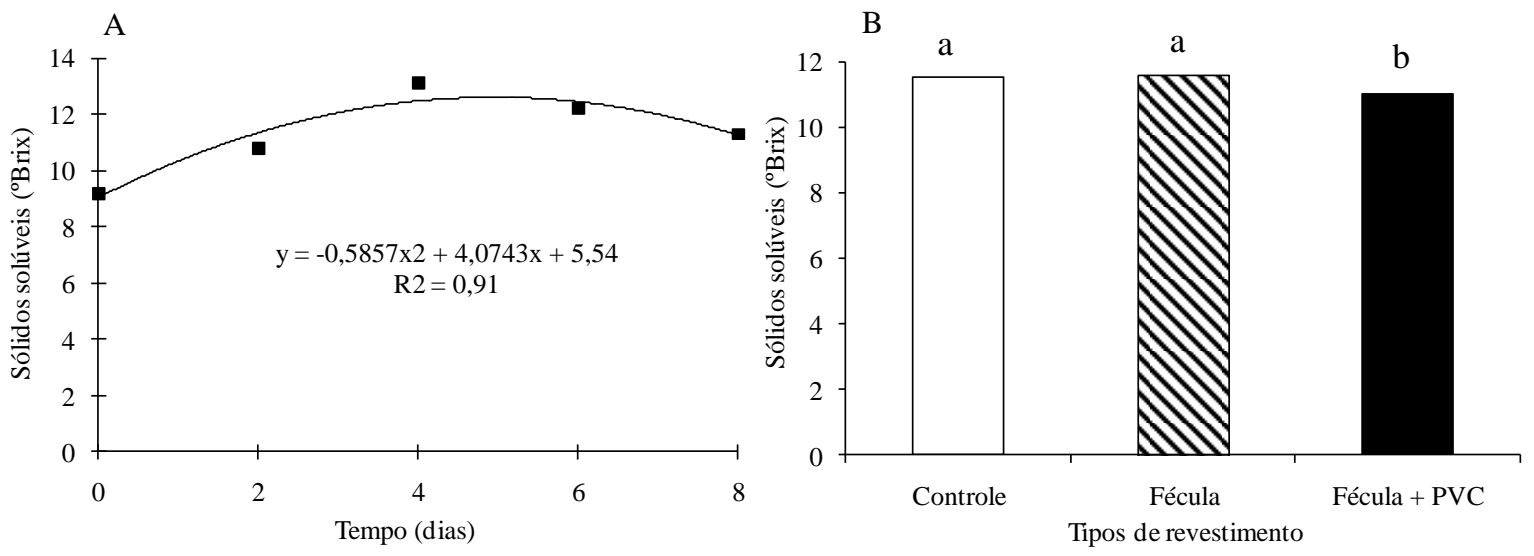

Figura 2. Valores de sólidos solúveis (A) e (B) de frutos de cajá recobertos com diferentes tipos de revestimentos e armazenados por 8 dias sob temperatura média de $29,7^{\circ} \mathrm{C}$ e UR de $59 \%$.

O aumento nos teores de SS ocorridos no presente trabalho poderá ser decorrente da

Cultura Agronômica, Ilha Solteira, v.25, n.4, p.409-418, 2016 
hidrólise do amido e principalmente das transformações nos açúcares solúveis. Os frutos tratados com fécula associado ao PVC apresentaram menores teores de SS provavelmente devido a um aumento nos processos metabólicos o que poderá ter levado a um maior consumo dos componentes dos SS no processo respiratório. Em trabalho realizado com cajá, Filgueiras et al. (2000) observaram que os frutos apresentaram teores médios de SS variando de 10,3 a $11,3{ }^{\circ}$ Brix quando estavam com a coloração da casca predominantemente verde e amarela, respectivamente. Os mesmos autores observaram ainda que houve um aumento dos teores de açúcares solúveis totais, açúcares redutores e uma redução nos teores de amido, esse último com pequenas concentrações encontradas nos frutos, levando a crer que o aumento nos SS deve ocorrer devido à conversão dos açúcares. Os SS são compostos por vários constituintes como ácidos, pectinas, compostos fenólicos e, principalmente, por açúcares. Sampaio et al. (2007), avaliando a atividade respiratória de cajás, observaram teores de SS variando de 9,1 (verde maduro) a 13,7 ${ }^{\circ}$ Brix (climatérico máximo); e por Bastos et al. (2008) de 8,2 a $10,7^{\circ}$ Brix.

Observou-se aumento nos teores de acidez titulável para todos os tipos de revestimento ao longo do armazenamento até o $6^{\circ}$ dia de armazenamento, com posterior decréscimo, principalmente para os frutos recobertos com fécula associado ao PVC (Figura 3A). Esse maior decréscimo no teor de acidez titulável ao final do experimento para os frutos recobertos com fécula associado ao PVC pode indicar que houve alteração nos processos metabólicos, levando ao maior consumo dos ácidos no processo respiratório. Segundo Chitarra e Chitarra (2005), a oscilação no teor de acidez titulável, ao longo do armazenamento de frutos, pode está relacionado aos processos bioquímicos do metabolismo respiratório, que tanto sintetiza quanto consome ácido como esqueleto de carbono. Variação de AT entre 0,6 a 2,6\% foi reportado por Maldonado-Astudillo et al. (2014), em S. mombin, sendo considerado como frutos ácidos.
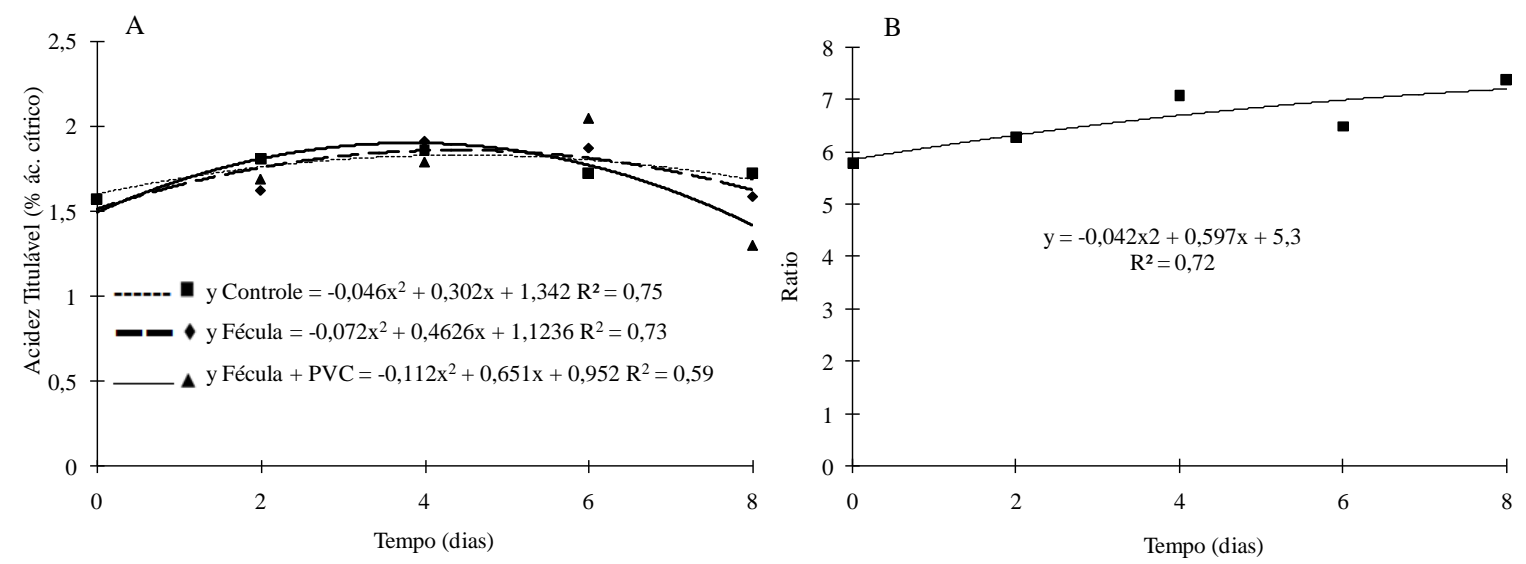

Figura 3. Valores de acidez titulável (A) e ratio (B) de frutos de cajá recobertos com diferentes tipos de revestimentos e armazenados por 8 dias sob temperatura média de 29,7 ${ }^{\circ} \mathrm{C}$ e UR de $59 \%$.

A relação SS/AT (Ratio) aumentou durante o armazenamento dos frutos com valor inicial e final de 5,8 e 7,4, respectivamente (Figura 3B). Essa variação ocorreu devido ao aumento muito mais acentuado nos teores de SS e uma redução nos teores de AT. Os

Cultura Agronômica, Ilha Solteira, v.25, n.4, p.409-418, 2016 
resultados encontrados no presente trabalho estão abaixo dos valores observados por Filgueiras et al. (2000) (11,23) e Tiburski et al. (2011) (10,2); e superior aos observado por Coelho et al. (2010) $(8,22$ a 9,0) e por Nunes et al. $(2011)(9,86)$. A quantificação da relação entre o teor de sólidos solúveis totais e a acidez titulável está relacionada com o balanço entre açúcares e ácidos presentes na fruta, sendo um importante indicativo do sabor. Ao se estabelecer essa relação, deve-se ter cuidado pelo fato de que algumas frutas, contendo baixos teores de ácidos e sólidos solúveis, apresentam elevadas relações SS/AT, o que pode conduzir a interpretações erradas a respeito da qualidade comestível.

Observou-se perda da qualidade externa ao longo do período experimental para todos os tipos de revestimentos estudados (Figura 4A). Para a coloração da casca, observou-se alteração da cor verde para laranja ao longo do período experimental com menor intensidade para os tratamentos fécula e fécula associado ao PVC que se mantiveram com grande parte da casca verde até o final do experimento (Figura 4B). A manutenção da cor verde esta relacionada, provavelmente, à menor penetração de oxigênio no interior do fruto, reduzindo a síntese de clorofilases que são mediadas pelo etileno. Vicentini et al. (1999), trabalhando com pimentão, constataram que a diminuição nos níveis de $\mathrm{O}_{2}$ e aumento do $\mathrm{CO}_{2}$ retardam a mudança da cor, significando que a película não é totalmente permeável ao $\mathrm{O}_{2}$ e $\mathrm{CO}_{2}$, embora o seja para a água. Segundo Chitarra e Chitarra (2005), a degradação da clorofila ocorre em função da ação da enzima clorofilase, mudanças do $\mathrm{pH}$, de ácidos e aumento de processos oxidativos.
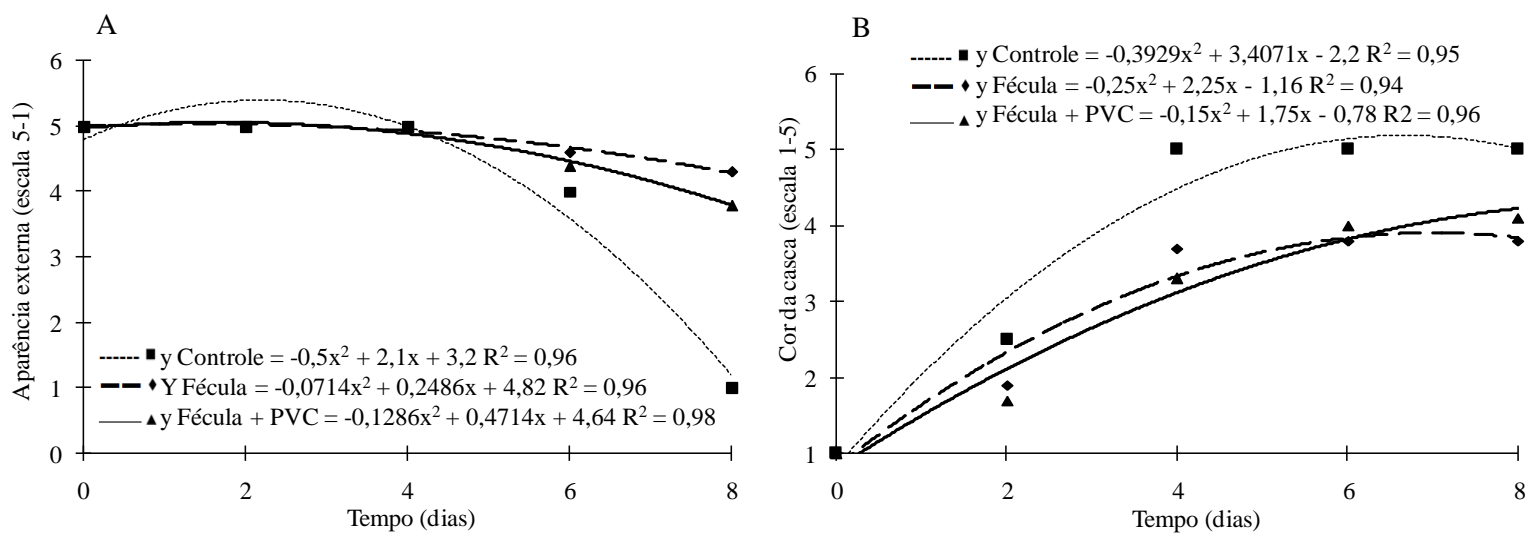

Figura 4. Valores de aparência externa (A) e de coloração da casca (B) de frutos de cajá recobertos com diferentes tipos de revestimentos e armazenados por 8 dias sob temperatura média de $29,7^{\circ} \mathrm{C}$ e UR de $59 \%$.

Segundo Maldonado-Astudillo et al. (2014) frutos de cajá armazenadas a $23-25{ }^{\circ} \mathrm{C}$ sua vida pós-colheita pode durar de dois a quatro dias, dependendo se eles foram colhidos no maduro ou o estádio verde, respectivamente. Nas condições do presente trabalho, os frutos de submetido a atmosfera modificada pode chegar até 8 dias, sem perdas em sua qualidade, já para o controle até o $6^{\circ}$ dia de armazenamento.

\section{CONCLUSÃO}

O uso de filmes plásticos foi eficiente em manter melhor aparência externa, reduzir a Cultura Agronômica, Ilha Solteira, v.25, n.4, p.409-418, 2016 
perda de massa e atrasar o amarelecimento dos frutos.

Os resultados obtidos com o uso de fécula de mandioca não se mostraram satisfatórios se comparados ao filme plástico, no entanto, apresentaram bons resultados quando comparados ao controle.

Baseado na aparência externa, o período de conservação do cajá foi de 8 dias para os frutos revestidos com fécula de mandioca isoladamente ou associado ao PVC e de 6 dias para o controle.

\section{AGRADECIMENTOS}

Os autores agradecem ao Instituto Frutal, IFCE (campus Limoeiro do Norte-CE), ao Conselho Nacional de Desenvolvimento Científico e Tecnológico (CNPq), à Coordenação de Aperfeiçoamento de Pessoal de Nível Superior (CAPES) e a Federação de Apoio à Pesquisa do Rio Grande do Norte (FAPERN), pelo apoio financeiro, suporte técnico e bolsas de estudo.

\section{REFERÊNCIAS BIBLIOGRÁFICAS}

AL-ATI, T.; HOTCHKISS, J. H. The role of packaging film permeselectivity in modified atmosphere packaging. Journal of Agricultural and Food Chemistry, Easton, v. 51, n. 14, p.4133-4138, 2003.

BASTOS, C. T. R. M.; LADEIRA, T. M. S.; ROGEZ, H.; PENA, R. S. Estudo da eficiência da pasteurizacão da polpa de taperebá (Spondias mombin). Alimentos e Nutrição, Araraquara, v. 19, n. 2, p.123-131, 2008.

CHITARRA, M. I. F.; CHITARRA, A. B. Pós-colheita de frutos e hortaliças: físiologia e manuseio. 2. ed. Lavras: UFLA, 2005. 785 p.

CISNERO-ZEVALLOS, L.; KROCHTA, J. M. Internal modified atmosphere of coated fresh fruit and vegetables: Understanding relative humidity effects. Journal of Food Science, Chicago, v. 67, n. 8, p.2792-2797, 2002.

COElHO, E. L.; SOUZA, P. A.; SOUZA, F. X.; SIlvA, M. S.; COSTA, J. T. A. Caracterização físico-química dos frutos dos clones de Cajazeira capuan e lagoa redonda submetidos à poda. Revista Verde, Mossoró, v. 5, n. 5, p.46-52, 2010.

DUAN, J.; WU, R.; STRIK, B. C.; ZHÃO, Y. Effect of edible coatings on the quality of fresh buelberries (Duke and Elliott) under commercial storage conditions. Postharvest Biology and Technology, Amsterdam, v. 59, n. 1, p.71-79, 2011.

DUVALL, C. S. On the origin of the tree Spondias mombin in Africa. Journal of Historical Geography, Texas, v. 32, n. 2, p.249-266, 2006.

EUM, H. L.; HWANG, D. K.; LINKE, M.; LEE, S. K.; ZUDE, M. Influence of edible coating on quality of plum (Prunus salicina Lindl. cv. 'Sapphire'). European Food

Cultura Agronômica, Ilha Solteira, v.25, n.4, p.409-418, 2016 
Research Technology, Dresden, v. 229, n. 3, p.427-434, 2009.

FILGUEIRAS, E. A. C.; MOURA, C. F. H.; ALVES, R. E. Cajá (Spondias mombin L.). 2000. Disponível em: http://www.ceinfo.cnpat.embrapa.br/arquivos/artigo_1554.pdf. Acesso em: 15 jul. 2010.

HOJO, E. T. D.; CARDOSO, A. D.; HOJO, R. H.; VILAS BOAS, E. V. B.; ALVARENGA, M. A. R. Uso de películas de fécula de mandioca e PVC na conservação pós-colheita de pimentão. Ciência Agrotecnologia, Lavras, v. 31, n. 1, p.184-190, 2007.

JANDEL SCIENTIFIC. User's Manual. Califórnia: Jandel Scientific, 1991. 280 p.

LEMOS, O. L.; REBOUÇAS, T. N. H.; JOSÉ, A. R. S.; VILA, M. T. R.; SILVA, K. S. Utilização de Biofilmes comestíveis na conservação de pimentão 'Magali $\mathrm{R}$ ' em duas condições de armazenamento. Bragantia, Campinas, v. 66, n. 4, p.693-699, 2007.

LIMA, M. A. C.; ALVES, R. E.; BISCEGLI, C. I.; FILGUEIRAS, H. A.; COCOZZA, F. D. M. Conservação de melões Gália 'Solar King' tratados com 1-metilciclopropeno. Horticultura Brasileira, Brasília, v. 22, n. 1, p.121-126, 2004.

MALDONADO-ASTUDILLO, Y. I.; ALIA-TEJACAL， I.; NÚÑEZ-COLÍN, C. A.; JIMÉNEZ-HERNÁNDEZ， J.; PELAYO-ZALDÍVAR， C.; LÓPEZ-MARTÍNEZ， V.; ANDRADE-RODRÍGUEZ, M.; BAUTISTA-BANOS, S.; VALLE-GUADARRAMA, S. Postharvest physiology and technology of Spondias purpurea L. and S. mombin L. Scientia Horticulturae, Canadá, v. 174, p.193-206, 2014.

MOREIRA, M. A. B.; SOUZA, F. X.; RITZINGER, C. H. S. P.; RITZINGER, R.; FIGUEIRAS, H. A. C. Cajá (Spondias mombin L. sin. Spondias lutea L.) In: VIEIRA NETO, R. D. (Ed.). Frutíferas potenciais para os tabuleiros costeiros e baixadas litorâneas. Aracaju: Embrapa Tabuleiros Costeiros/ Emdagro, 2002. cap. 2, p. 21-44.

MORETTI, C. L.; PINELI, L. L. O. Qualidade química e física de berinjelas submetidas a diferentes tratamentos pós-colheita. Ciência e Tecnologia de Alimentos, Campinas, v. 25, n. 2, p.339-344. 2005.

NUNES, J. A. R.; SANTANA, F. F.; GOMES, R. L. F.; LOPES, A. C. A.; PEREIRA, M. M. G.; SOARES, E. B. Stratified mass selection of promising Spondias mombin clones in a commercial crop. Crop Breeding and Applied Biotechnology, Londrina, v. 11, p.141-148, 2011.

PEREIRA, M. E. C.; SILVA. A. S.; BISPO, A. S. R.; SANTOS, D. B.; SANTOS, S. B.; SANTOS, V. J. Amadurecimento de mamão formosa com revestimento comestível à base de fécula de mandioca. Ciência e Agrotecnologia, Lavras, v. 30, n. 6, p.1116-1119, 2006.

RIBEIRO, C.; VICENTE, A. A.; TEIXEIRA, J. A.; MIRANDA, C. Optimization of edible coating composition to retard strawberry fruit senescence. Postharvest Biology and Technology, Amsterdam, v. 44, n. 1, p.63-70, 2007.

SAMPAIO, S. A.; BORA, P. S.; HOLSCHUH, H. J.; SILVA, S. M. Postharvest respiratory activity and changes in some chemical constituents during maturation of yellow mombin

Cultura Agronômica, Ilha Solteira, v.25, n.4, p.409-418, 2016 
(Spondias mombin) fruit. Ciência e Tecnologia de Alimentos, Campinas, v. 27, n. 3, p.511515, 2007.

SARMENTO, D. H. A.; SOUZA, P. A.; SARMENTO, J. D. A.; FREITAS, R. V. S.; SALGADO FILHO, M. Armazenamento de banana 'Prata Catarina' sob temperatura ambiente recobertas com fécula de mandioca e PVC. Revista Caatinga, Mossoró, v. 28, n. 2 , p.235-241, 2015.

SOUZA, P. A.; AROUCHA, E. M. M.; SOUZA, A. E. D.; COSTA, A. R. F. C.; FERREIRA, G. S.; BEZERRA NETO, F. Conservação pós-colheita de berinjela com revestimentos de fécula de mandioca ou filme de PVC. Horticultura Brasileira, Brasília, v. 7, n. 2, p.235-239, 2009.

TIBURSKI, J. H.; ROSENTHAL, A.; DELIZA, R.; GODOY, R. L. O.; PACHECO, S. Nutritional properties of yellow mombin (Spondias mombin L.) pulp. Food Research International, Toronto, v. 44, n. 7, p.2326-2331, 2011.

VICENTINI, N. M.; CASTRO, T. M. R.; CEREDA, M. P. Influência de películas de fécula de mandioca na qualidade pós-colheita de frutos de pimentão (Capsicum annuum L.). Ciência e Tecnologia de Alimentos, Campinas, v. 19, n. 1, p.127-130, 1999.

VILA, M. T. R.; LIMA, L. C. O.; VILAS BOAS, E. V. B.; HOJO, E. T. D.; RODRIGUES, L. J.; PAULA, N. R. F. Caracterização química e bioquímica de goiabas armazenadas sob refrigeração e atmosfera modificada. Ciência e Agrotecnologia, Lavras, v. 31, n. 5, p.14351442, 2007.

ZENEBON, O.; PASCUET, N.S.; TIGLEA, P. (Coord.). Métodos físico-químicos para análise de alimentos. São Paulo: Instituto Adolfo Lutz, 2008. 1020 p. Versão eletrônica. Disponível em: http://www.crq4.org.br/sms/files/file/analisedealimentosial_2008.pdf. Acesso em: 29 nov. 2016. 